\title{
Relationship of place of death with care capacity and accessibility: a multilevel population study of system effects on place of death in Norway
}

\author{
Jorid Kalseth ${ }^{*}$ (iD and Thomas Halvorsen
}

\begin{abstract}
Background: While the majority of deaths in high-income countries currently occur within institutional settings such as hospitals and nursing homes, there is considerable variation in the pattern of place of death. The place of death is known to impact many relevant considerations about death and dying, such as the quality of the dying process, family involvement in care, health services design and health policy, as well as public versus private costs of end-of-life care. The objective of this study was to analyse how the availability and capacity of publicly financed home-based and institutional care resources are related to place of death in Norway.
\end{abstract}

Methods: This study utilized a dataset covering all deaths in Norway in the years 2003-2011, contrasting three places of death, namely hospital, nursing home and home. The analysis was performed using a multilevel multinomial logistic regression model to estimate the probability of each outcome while considering the hierarchical nature of factors affecting the place of death. The analysis utilized variation in health system variables at the local community and hospital district levels. The analysis was based on data from two public sources: the Norwegian Cause of Death Registry and Statistics Norway.

Results: Hospital accessibility, in terms of short travel time and hospital bed capacity, was positively associated with the likelihood of hospital death. Higher capacity of nursing home beds increased the likelihood of nursing home death, and higher capacity of home care increased the likelihood of home death. Contrasting three alternative places of death uncovered a pattern of service interactions, wherein hospital and home care resources together served as an alternative to end-of-life care in nursing homes.

Conclusions: Norway has a low proportion of home deaths compared with other countries. The proportion of home deaths varies between local communities. Increasing the availability of home care services is likely to enable more people to die at home, if that is what they prefer.

Keywords: Place of death, End-of-life care, Hospital, Nursing home, Home death, Health system, Health services, Long-term care, Accessibility, Capacity

* Correspondence: jorid.kalseth@sintef.no

Department of Health Research, SINTEF Digital, P.O. Box 4760, Sluppen,

NO-7465 Trondheim, Norway

C C The Author(s). 2020 Open Access This article is licensed under a Creative Commons Attribution 4.0 International License, which permits use, sharing, adaptation, distribution and reproduction in any medium or format, as long as you give appropriate credit to the original author(s) and the source, provide a link to the Creative Commons licence, and indicate if changes were made. The images or other third party material in this article are included in the article's Creative Commons licence, unless indicated otherwise in a credit line to the material. If material is not included in the article's Creative Commons licence and your intended use is not permitted by statutory regulation or exceeds the permitted use, you will need to obtain permission directly from the copyright holder. To view a copy of this licence, visit http://creativecommons.org/licenses/by/4.0/. The Creative Commons Public Domain Dedication waiver (http://creativecommons.org/publicdomain/zero/1.0/) applies to the data made available in this article, unless otherwise stated in a credit line to the data. 


\section{Background}

The organization of end-of-life (EoL) care in highincome countries has undergone major shifts. Increasing capacity in institutional care during the twentieth century led to fewer home deaths and a corresponding increase in hospital and nursing home deaths [1-3]. While the proportion of nursing home deaths increased, the trend reversed for hospital deaths in countries such as the US, Canada and England, where the proportion of home deaths started to increase towards the end of the twentieth century [4-7]. Norway showed the same trend in hospital and nursing home deaths, partly due to changes in the EoL care for growing patient groups such as patients with cancer, who were increasingly offered this care in nursing home settings instead of hospitals. Moreover, this development coincided with major demographic and epidemiological trends that also led to the continuing decrease in the rate of home deaths in Norway during the first decade of the twenty-first century [8].

People generally wish to die at home [4, 9], but the majority of deaths in high-income countries still occur within institutional settings [10]. While common demographic and epidemiological trends are important determinants in the demand for EoL care [8], there is still considerable variation in how this care is organized [11]. A core value for palliative care has been to enable people to make choices about their EoL care and place of death (PoD) [12]. Some conditions require that EoL care be administered within a hospital setting, while adequate care can be provided more easily in the patient's home for other conditions. Nevertheless, to what degree the PoD is influenced by availability of institutional or home-based care is an open question. If, for example, resources are steered towards home-based care, does this have the potential to provide more people with EoL care in their homes and eventually increase the proportion of home deaths? The limited existing literature on the relationship between service accessibility, capacity and PoD is divided. Most studies refer to specific subpopulations of people who have died, such as patients with cancer [13], those with dementia [14] or very old persons [15], or to specific settings, i.e. excluding important PoDs such as nursing homes [11]. In addition, the groups compared may be heterogeneous, i.e. when the analyses involve only binomial contrasts [16].

The objective of this study was to analyse how the availability and capacity of home-based and institutional care resources are related to PoD, utilizing a dataset covering all deaths in a national population, i.e. covering all ages and causes of death. We contrasted three PoDs, namely hospital, nursing home and home, while considering the hierarchical nature of factors affecting the PoD. More specifically, we wished to examine how the availability and capacity of care resources in Norwegian municipalities and hospital districts were associated with the PoD, controlling for individual and contextual factors related to the demand for EoL care. Our analysis covered the entire population, i.e. all deaths in Norway, for the period 2003-2011. This approach enabled us to consider both time variation and cross-sectional variation in service availability and capacity.

\section{Methods}

In the analysis of PoD decisions, we decided to build on Andersen and Newman's [17] framework for health service utilization, which models individual health care consumption as a function of individual characteristics and the characteristics of the environment where the individual lives. The framework separates individual determinants of health care utilization into factors predisposing individuals to certain services such as age and sex, enabling factors such as marital status and income level, and need factors reflecting frailty and the level of illness. Societal determinants (norms and technology) and the health services system are the two major environmental or context dimensions influencing health service utilization. Resources, that is, the labour and capital devoted to providing services, and their organization, i.e. how the resources are controlled and coordinated, are the central elements in the health services system. The resource component involves both the volume of available resources in the system and their geographical distribution. The organization of services comprises accessibility, related to financial aspects as well as to travel times and waiting times, and structure, which relates to characteristics of the system that determine the patients' journey through the system such as medical practices and referral systems. Norway has a publicly funded health and long-term care system, organized into two administrative levels. The first level comprises primary health care and long-term care (LTC). This includes general practitioners, home-based services and nursing home care and is the responsibility of the municipalities. The second level, hospital services and other specialist health care, is the responsibility of the state and is organized within hospital districts under regional health authorities. EoL care is organized within the regular service system. Service utilization in the last months, weeks and days of life occurs in hospitals, nursing homes or at home.

In line with Andersen and Newman's [17] framework for health service utilization, we sought to analyse PoD as a response to individual and system characteristics. Local contextual factors, i.e. population characteristics at the municipal level, represent the societal determinants in our model. 
Hence, in modelling the choice between PoD in patients' homes, nursing homes and hospitals, we built on the assumption that PoD decisions can be expressed as a function of patient characteristics, population characteristics of municipalities, the capacity of home-based care and institutional care within municipalities, the capacity of hospital care within hospital districts and the geographical accessibility to services in terms of travel times measured at the municipal level. In the form of an equation, it can be expressed as:

$$
P\left(P o D_{i}\right)=f\left(I_{i}, P_{\mathrm{m}}, C_{m}, C_{h}, A_{m}\right),
$$

where the discrete individual-level ${ }_{[i]}$ probability of PoD depends on a vector of individual characteristics $I$ and municipal-level $[\mathrm{m}]$ vectors of population characteristics $P$, municipal service capacities $C$ and accessibility $A$. In addition, at the hospital district level ${ }_{[h]}$, there is a vector of hospital capacity characteristics $C$.
The variables at each level, the data sources and number of observations are shown in Table 1.

The operationalization of the model was restricted by data availability. The analysis was based on data from two public sources: the Norwegian Cause of Death Registry (NCoDR) and Statistics Norway (SSB). Data on the decedents' PoD, our dependent variable, were collected from the NCoDR. We only considered PoD at home, in nursing homes and in hospitals. 'Nursing homes' included all institutional deaths not included in the hospital category. The NCoDR provided all individual-level characteristics $\left(I_{i}\right)$ in the form of year of death, age at death, gender, marital status and main underlying cause of death $(\mathrm{CoD})$. The remaining data were collected from SSB, except for data on travel time to hospitals, which were available from a previous study [18]. Contextual variables included municipal population characteristics $\left(P_{m}\right)$, such as the death rate, demographic (age) distribution, marriage rates, female employment rates

Table 1 Variables, data sources and number of observations

\begin{tabular}{|c|c|c|c|}
\hline Level & Variable & Source & $\mathbf{N}(2003-2011)$ \\
\hline \multirow[t]{8}{*}{ Individual } & PoD (Hospital, Home or Nursing home) & \multirow[t]{8}{*}{ NCoDR } & \multirow{4}{*}{$\begin{array}{l}351,907 \text { ( } 2465 \text { missing higher-level } \\
\text { variables) }\end{array}$} \\
\hline & Predisposing & & \\
\hline & Age (six groups) & & \\
\hline & Gender & & \\
\hline & Enabling & & \multirow[t]{4}{*}{ Analyses: $100^{*} 20 \%$ samples } \\
\hline & Marital status (four groups) & & \\
\hline & Need & & \\
\hline & CoD (six groups) & & \\
\hline \multirow[t]{15}{*}{ Municipal } & Population characteristics (context) & \multirow[t]{6}{*}{ SSB } & \multirow{15}{*}{$\begin{array}{l}423-428 \text { (excluding municipalities with } \\
\text { missing data) }\end{array}$} \\
\hline & - Death rate (per 1000 population) & & \\
\hline & - Age $67-79,80-89$ and $90+$ years (\% in total population) & & \\
\hline & - Married (\% in population aged 18+) & & \\
\hline & $\begin{array}{l}\text { - Female employment (> } 30 \mathrm{~h} / \text { week) (\% in female population } \\
\text { aged } 16-66 \text { years) }\end{array}$ & & \\
\hline & - Population size (five dummy groups) & & \\
\hline & Accessibility & \multirow{9}{*}{$\begin{array}{l}\text { (Travel time to hospital - } \\
\text { own data) }\end{array}$} & \\
\hline & - Travel time to municipal centre & & \\
\hline & - Travel time to local hospital & & \\
\hline & $\begin{array}{l}\text { - Travel time to local+ hospital (hospital with additional } \\
\text { functions) }\end{array}$ & & \\
\hline & - Travel time to regional hospital & & \\
\hline & Capacity & & \\
\hline & - Nurses in LTC (FTP per 100 population aged 67+ years) & & \\
\hline & - Relative size home care (\% of total LTC labour costs) & & \\
\hline & - Nursing home beds (per 100 population aged 80+ years) & & \\
\hline \multirow{2}{*}{$\begin{array}{l}\text { Hospital } \\
\text { district }\end{array}$} & Capacity & \multirow[t]{2}{*}{ SSB } & \multirow[t]{2}{*}{43} \\
\hline & - Hospital beds (somatic beds, per 1000 population) & & \\
\hline
\end{tabular}


and population size. Health service system resources included volume measures of service capacity distributed at the municipal and hospital district levels. Municipal service capacity $\left(C_{m}\right)$ included a measure of the homebased care capacity, in the form of labour costs of home-based care as a percentage of total labour costs within municipal LTC, and a measure of institutional care capacity, in the form of the number of nursing home beds per 100 population aged $80+$ years. We also included municipal LTC nursing capacity in the form of a count of full-time nursing positions per 100 population aged $67+$ years. Our final capacity measure was the (somatic) hospital bed rate at the hospital district level $\left(C_{h}\right)$. Service system organization was captured both by including variables for different services at different levels and by including variables reflecting geographical accessibility. Average travelling time to the municipal centre was included as a proxy for distance to municipal services. Hospitals may have different functions, and thus we separated them into local hospitals, hospitals with additional speciality functions and regional hospitals. The latter two types also serve as local hospitals for some municipalities. Hospital districts typically include several hospitals. A regional hospital is found in four of the hospital districts. Accessibility to hospital care included four variables: i) whether a hospital is located in the municipality, ii) average travel time from municipal centre to nearest local hospital, iii) nearest hospital with additional speciality functions and iv) nearest regional hospital.

The collected data were structured into four measurement levels. Hospital districts were at the highest level. The hospital districts encompass a varying number of municipalities, which represent the second highest level. Within these two administrative levels, we have repeated yearly measurements (third level), within which the individual-level data were nested (fourth level). Because a multilevel analysis was especially suited to estimate models of hierarchical data structures such as this and because PoD had three discrete outcomes, we selected a multinomial logistic regression model to estimate the probability of each outcome.

Of the approximately 374,000 deaths in Norway in the years 2003-2011, approximately 22,000 were excluded either due to missing PoD (1.5\%) or belonging to the category 'other places' (4.4\%). Another 2465 were excluded due to missing information on municipal-level characteristics. The number of municipalities included from year to year varies from 423 to 428 due to both missing data and municipal mergers. Each municipality was assigned to a hospital district, and we maintained the number of hospital districts as 43 over the period. The municipality of Oslo (the capital) has historically been divided into several acute hospital districts, but because the organization of the hospital catchment areas in the capital area had undergone multiple changes during the study period, we treated the hospitals in the capital area as one. The data had a four-level nested structure (individual, year, municipality and hospital district) and the dependent variable was multinomial (death at home, in hospital and in nursing home). The analyses were performed with both hospital and nursing home as a reference category to capture all three relevant comparisons. Because of the sheer size of our dataset, estimation capacity restraints made it difficult to perform multilevel multinomial regression analysis on the entire sample. Instead, we drew 100 random 20\% bootstrap samples $(N=69,887)$ within year, hospital district and PoD. We report the mean results for the relative risk ratio (RRR). The 95\% confidence interval for the mean and standard error of the RRR from the 100 regressions were at the mean value or with \pm 0.01 for all variables except for the mean RRR of home versus nursing home death for the age group $0-49$ years, which were within \pm 0.03 . The analyses were performed using MLwiN version 3.00 and STATA/MP 14.0.

\section{Results \\ PoD}

In the study period, $15.8 \%$ of people died at home, $40.1 \%$ in hospitals and $44.1 \%$ in nursing homes (Table 2). Hence, the majority of deaths occurred within institutional settings. The percentages for different PoDs varied between years, municipalities and hospital districts. Figure 1 shows the differences in the distribution of PoD at the municipal level by year (controlling for hospital district) and by hospital district (controlling for year). The average proportion of nursing home deaths increased, and the proportion of home deaths and hospital deaths decreased over the study period. The average percentage of hospital deaths at the municipal level was more than 10 percentage points higher in the capital area than in the hospital districts with lowest average proportion of hospital deaths.

\section{Decedent characteristics}

Of the approximately 350,000 decedents included in this study, $53 \%$ were women, nearly $60 \%$ were aged above 80 years, $43 \%$ were widowed, $35 \%$ died of diseases of the circulatory system and almost $30 \%$ died of cancer (Table 2). The composition of the deceased population differed between the PoDs, with the proportion of old, widowed and women being lowest for home deaths and highest for nursing home deaths.

\section{Context characteristics}

There was substantial variation in the municipal context, in terms of mortality rates, age composition, female 
Table 2 Descriptive statistics (decedents' characteristics, excluding deaths in 'other places'; years 2003-2011)

\begin{tabular}{|c|c|c|c|c|}
\hline & \multicolumn{4}{|c|}{ Place of death } \\
\hline & Home & Hospital & Nursing home & Total \\
\hline N & 55,668 & 141,091 & 155,148 & 351,907 \\
\hline$\%$ & 15.8 & 40.1 & 44.1 & 100.0 \\
\hline Year \% p10-p90 & $14.9-16.5$ & $36.4-42.5$ & $40.9-48.5$ & \\
\hline Municipality \% p10-p90 & $11.9-21.2$ & $27.3-45.7$ & $37.9-56.7$ & \\
\hline \multirow[t]{2}{*}{ Hospital district \% p10-p90\% } & $13.5-17.9$ & $36.1-42.8$ & $40.6-48.1$ & \\
\hline & $\%$ & $\%$ & $\%$ & $\%$ \\
\hline Gender $=$ Women & 41.8 & 47.2 & 62.0 & 52.9 \\
\hline Gender $=$ Men & 58.2 & 52.8 & 38.0 & 47.1 \\
\hline Age $=0-49$ years & 10.4 & 5.7 & 0.6 & 4.2 \\
\hline Age $=50-59$ years & 11.2 & 7.4 & 1.6 & 5.4 \\
\hline Age $=60-69$ years & 16.8 & 14.5 & 4.7 & 10.5 \\
\hline Age $=70-79$ years & 22.7 & 24.9 & 15.5 & 20.4 \\
\hline Age $=80-89$ years & 28.8 & 37.0 & 46.9 & 40.1 \\
\hline Age $=90+$ years & 10.1 & 10.6 & 30.8 & 19.4 \\
\hline Marital status $=$ Married & 36.4 & 43.6 & 25.9 & 34.7 \\
\hline Marital status $=$ Widowed & 30.1 & 34.3 & 56.3 & 43.4 \\
\hline Marital status = Divorced & 15.0 & 10.4 & 7.1 & 9.7 \\
\hline Marital status = Unmarried & 18.5 & 11.6 & 10.7 & 12.3 \\
\hline CoD = Cancer & 19.7 & 33.8 & 24.4 & 27.4 \\
\hline CoD $=$ Dementia & 2.2 & 0.6 & 12.5 & 6.1 \\
\hline CoD $=$ Circulation & 40.3 & 34.5 & 34.2 & 35.3 \\
\hline $\mathrm{CoD}=$ Respiratory & 7.7 & 10.1 & 10.7 & 10.0 \\
\hline CoD $=$ External & 11.8 & 4.8 & 2.8 & 5.0 \\
\hline $\mathrm{CoD}=$ Other & 18.3 & 16.2 & 15.3 & 16.1 \\
\hline
\end{tabular}

p10 10th percentile, $p 90$ 90th percentile, $C o D$ cause of death

work participation and population size. Approximately half of the municipalities had less than 5000 inhabitants, and only $3 \%$ had more than 50,000 inhabitants (Table 3).

\section{System characteristics}

The average travel time to municipal centres was $9 \mathrm{~min}$. The average travel time to the nearest local hospital was $72 \mathrm{~min}$, while the corresponding time to hospitals with specialized functions and to regional hospitals was 2.5 and $4 \mathrm{~h}$, respectively, and $12 \%$ of the municipalities hosted a hospital within their borders. There were on average 3.9 nurses per 100 population aged $67+$ years in municipal LTC services, 21.5 nursing home beds per 100 population aged $80+$ years, and approximately $50 \%$ of LTC salary budgets were spent on home care services. Finally, there were on average 2.6 hospital beds per 1000 population in the hospital catchment areas (Table 3).

\section{Estimation results}

Table 4 presents the results from the multinomial regression model, wherein PoD was estimated as the outcome of three contrasts: home/hospital, nursing home/hospital and home/nursing home.

Our results suggest that the likelihood of home death increased with the capacity of home services, in form of the relative budget size of home care, and decreased with the bed capacity of nursing homes. Furthermore, the likelihood of a nursing home death versus a hospital death was not affected by nursing home bed capacity, but it decreased with the relative size of home care budgets. Higher nursing capacity in municipal LTC services, in the form of full-time positions, increased the likelihood of nursing home death relative to both hospital death and home death. Finally, higher bed capacity within hospitals increased the likelihood of both hospital and home death versus nursing home death, but it had no bearing on the likelihood of home versus hospital death.

In terms of accessibility, living in proximity to a hospital (within a municipality with a hospital or with low average travel time to the local hospital) increased the likelihood of dying in a hospital. Increased average travel 
(a) Year

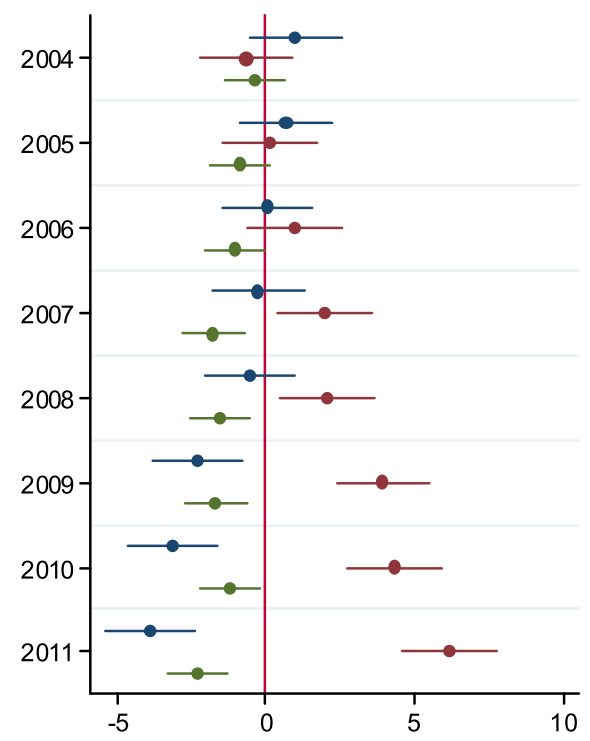

(b) Hospital district

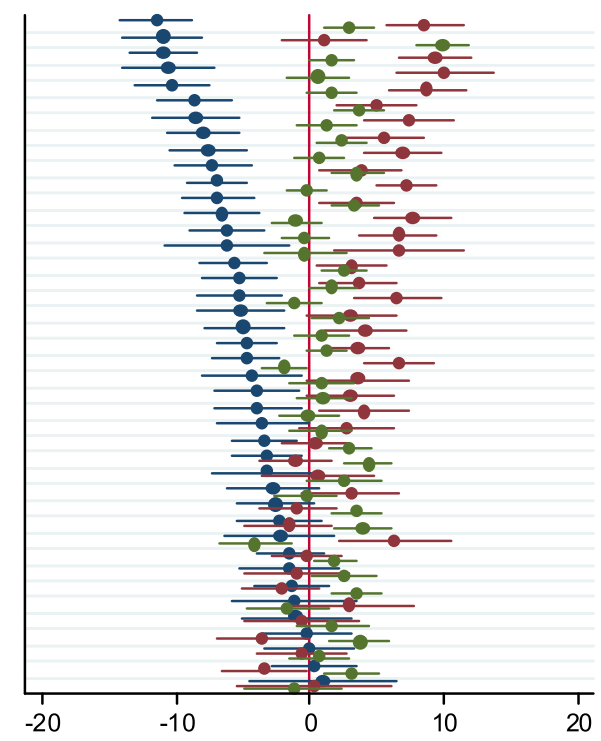

- Home

Fig. 1 Differences in distribution (\%) of place of death in hospital, nursing home and at home at municipal level, by (a) year, reference = 2003 (controlling for hospital district), and (b) hospital district, reference = capital area (controlling for year)

Table 3 Descriptive statistics (municipal and hospital district-level variables; years 2003-2011)

\begin{tabular}{|c|c|c|}
\hline & Mean & Standard deviation \\
\hline \multicolumn{3}{|l|}{ Municipal level ( $\boldsymbol{N}=\mathbf{3 8 3 7}$ [= number of municipalities times number of years]) } \\
\hline Death rate (per 1000 population) & 10.5 & 3.3 \\
\hline Age 67-79years (per 100 population) & 9.8 & 2.0 \\
\hline Age 80-89years (per 100 population) & 4.7 & 1.3 \\
\hline Age $90+$ years (per 100 population) & 0.9 & 0.4 \\
\hline Married (per 100 population aged 18+ years) & 48.6 & 4.9 \\
\hline Female employment (> $30 \mathrm{~h} /$ week) (per 100 women aged 16-66) years) & 39.1 & 6.3 \\
\hline Population 5-99,000 & $21.0^{\mathrm{a}}$ & \\
\hline Population 10-19,999 & $13.2^{\mathrm{a}}$ & \\
\hline Population 20-49,999 & $8.1^{\mathrm{a}}$ & \\
\hline Population $50,000+$ & $3.0^{\mathrm{a}}$ & \\
\hline Travel time to municipal centre (average, minutes) & 9.0 & 6.9 \\
\hline Hospital located in municipality & $12.2^{\mathrm{a}}$ & \\
\hline Travel time to local hospital ${ }^{\mathrm{b}}$ & 71.8 & 68.5 \\
\hline Travel time to local+ hospital ${ }^{b}$ & 149.5 & 163.1 \\
\hline Travel time to regional hospital ${ }^{b}$ & 244.4 & 181.5 \\
\hline Nurses in LTC (per 100 population aged 67+ years) & 3.9 & 1.4 \\
\hline Relative size homecare (\% labour costs) & 49.2 & 13.8 \\
\hline Nursing home beds (per 100 population aged $80+$ years) & 21.5 & 8.2 \\
\hline \multicolumn{3}{|l|}{ Hospital level ( $\boldsymbol{N}=\mathbf{3 8 7}$ [= number of hospital districts times number of years]) } \\
\hline Hospital beds (somatic beds, per 1000 population) & 2.6 & 0.8 \\
\hline
\end{tabular}


Table 4 Multilevel multinomial logistic regression (relative risk ratio ${ }^{d}$ )

\begin{tabular}{|c|c|c|c|}
\hline & $\begin{array}{l}\text { Home versus hospital } \\
\text { death }\end{array}$ & $\begin{array}{l}\text { Nursing home versus } \\
\text { hospital death }\end{array}$ & $\begin{array}{l}\text { Home versus nursing } \\
\text { home death }\end{array}$ \\
\hline \multicolumn{4}{|l|}{ Individual level } \\
\hline \multicolumn{4}{|l|}{ Gender $($ Ref $=$ Men $)$} \\
\hline Women & $0.84^{c}$ & $1.32^{c}$ & $0.66^{c}$ \\
\hline \multicolumn{4}{|l|}{ Age $($ Ref $=90+$ years $)$} \\
\hline $0-49$ years & $1.80^{c}$ & $0.04^{c}$ & $46.30^{c}$ \\
\hline $50-59$ years & $2.03^{c}$ & $0.08^{c}$ & $26.4^{c}$ \\
\hline 60-69 years & $1.64^{c}$ & $0.13^{c}$ & $13.43^{c}$ \\
\hline 70-79 years & $1.2^{c}$ & $0.25^{c}$ & $4.73^{c}$ \\
\hline 80-89 years & $0.89^{c}$ & $0.49^{c}$ & $1.82^{c}$ \\
\hline \multicolumn{4}{|l|}{ Marital status (Ref = Unmarried) } \\
\hline Married & $0.7^{c}$ & $0.57^{c}$ & $1.22^{c}$ \\
\hline Widowed & $0.83^{c}$ & $0.82^{c}$ & 0.99 \\
\hline Divorced & 1.02 & $0.84^{c}$ & $1.14^{c}$ \\
\hline \multicolumn{4}{|l|}{ Cause of death (Ref = Other) } \\
\hline Cancer & $0.49^{c}$ & $1.23^{c}$ & $0.37^{c}$ \\
\hline Dementia & $4.08^{c}$ & $16.01^{c}$ & $0.25^{c}$ \\
\hline Circulation & $1.16^{c}$ & $0.86^{c}$ & $1.44^{c}$ \\
\hline Respiratory & $0.73^{c}$ & 0.99 & $0.77^{c}$ \\
\hline External & $1.73^{c}$ & $0.58^{c}$ & $2.54^{c}$ \\
\hline \multicolumn{4}{|l|}{ Municipal level } \\
\hline \multicolumn{4}{|l|}{ Population characteristics (context) } \\
\hline Death rate & 1.01 & 1.01 & 1.00 \\
\hline Age $67-79$ years & 1.02 & $1.04^{\mathrm{b}}$ & 0.99 \\
\hline Age $80-89$ years & $0.94^{\mathrm{a}}$ & 0.98 & 0.97 \\
\hline Age $90+$ years & 1.08 & 1.07 & 1.03 \\
\hline Married & 1.00 & $0.98^{c}$ & $1.01^{c}$ \\
\hline Female employment & $0.99^{c}$ & $1.01^{c}$ & $0.98^{c}$ \\
\hline Population 5-99,000 & 0.99 & 0.99 & 1.01 \\
\hline Population 10-19,999 & $0.89^{b}$ & 0.93 & 0.97 \\
\hline Population 20-49,999 & $0.89^{\mathrm{a}}$ & 0.93 & 0.95 \\
\hline Population $50,000+$ & 0.92 & 0.89 & 1.03 \\
\hline \multicolumn{4}{|l|}{ Accessibility $^{\mathrm{e}}$} \\
\hline Ttt municipal centre (average, minutes) & 1.00 & 1.00 & 1.00 \\
\hline Hospital in municipality & $0.83^{c}$ & $0.79^{c}$ & 1.05 \\
\hline Ttt local hospital ${ }^{f}$ & $1.02^{c}$ & $1.02^{c}$ & 1.00 \\
\hline Ttt local+ hospital ${ }^{f}$ & $0.99^{b}$ & $0.98^{c}$ & $1.01^{\mathrm{b}}$ \\
\hline Ttt regional hospital ${ }^{f}$ & 1.00 & 1.00 & 1.00 \\
\hline \multicolumn{4}{|l|}{ Capacity } \\
\hline Nurses in LTC & $1.03^{\mathrm{a}}$ & $1.08^{c}$ & $0.96^{c}$ \\
\hline Relative size home care (\%budget/10) & $1.03^{\mathrm{a}}$ & $0.96^{c}$ & $1.07^{c}$ \\
\hline Nursing home beds (per 100 pop 80+ years) & $0.98^{c}$ & 1.00 & $0.98^{c}$ \\
\hline \multicolumn{4}{|l|}{ Hospital level } \\
\hline \multicolumn{4}{|l|}{ Capacity } \\
\hline Hospital beds & 0.99 & $0.92^{c}$ & $1.09^{c}$ \\
\hline Constant & 0.91 & $5.1^{c}$ & $0.20^{c}$ \\
\hline
\end{tabular}

a Significance at 0.1 level, ${ }^{\mathrm{b}}$ Significance at 0.05 level, ' Significance at 0.01 level

${ }^{d}$ Mean of $10020 \%$ samples. Four levels: Decedent $(N=69,887)$ within Year (2003-2011) within Municipality $(N=423-428)$ within Hospital district $(N=43)$

${ }^{\mathrm{e}} \mathrm{Ttt}$, Travel time to

${ }^{f}$ Measured in units of $15 \mathrm{~min}$ 
time to hospitals with specialized functions increased the likelihood of hospital and home deaths versus nursing home death. No significant associations were found for average travel time to the municipal centre or nearest regional hospital.

Of the context variables included at the municipal level, we found that a higher population proportion of young elderly (67-79 years) increased the likelihood of nursing home death versus hospital death, whereas an increased proportion of elderly in the age group 80-89 years reduced the likelihood of home death versus hospital death. Populations with higher marriage rates were associated with lower likelihood of nursing home death, while higher proportions of female employment increased the likelihood of nursing home death, and also reduced the likelihood of home death versus hospital death. The likelihood of home versus hospital deaths was lower in municipalities with a population between 10,000 and 50,000 compared with the smallest municipalities with a population under 5000 .

The results of the individual-level variables gender and age were consistent with findings of the descriptive statistics, i.e. that the likelihood of home death was lower for women than men and decreased with age (except for the elderly population aged 89-90 years having a lower likelihood of home death versus hospital death than those aged $90+$ years), while the opposite relationships were found for nursing home deaths. Unmarried people were more likely to die in nursing homes than married, widowed and divorced people. Unmarried people were also more likely to die at home as opposed to hospital than married and widowed persons. The results for $\mathrm{CoD}$ showed that the likelihood of nursing home death was very high for dementia and high for cancer and respiratory diseases but low for diseases of the circulatory system and external causes. The relative risk of home death compared with that of hospital death was higher for dementia, circulatory diseases and external causes, and lower for cancer and respiratory diseases.

\section{Discussion}

Similar to many high-income countries, there was a significant decrease in the rate of hospital deaths and an increase in nursing home deaths in Norway in the period under study. This trend can partly be attributed to demographic and epidemiological shifts affecting the composition of decedents. More female deaths, higher age at death and fewer deaths caused by circulatory diseases were some of the underlying causes [8]. This study confirmed the importance of individual factors such as age, gender, marital status and $\mathrm{CoD}$ as predictors of PoD, but the main contribution of this study was its exploration of the relevance of contextual and system-level determinants.

\section{PoD and service system capacity and accessibility}

Accessibility and capacity of services were clearly associated with PoD. The results revealed both expected patterns of 'pull factors', as well as indicated service interactions affecting PoD. These are summarized in Table 5.

As expected, hospital accessibility (living close to a local hospital) and capacity (somatic bed rate) increased the likelihood of hospital death. High capacity of nursing home beds increased the likelihood of nursing home death, while a high proportion of LTC spending on home care increased the likelihood of home death. More surprising, perhaps, was the finding that long travel time to the nearest hospital with more specialized functions appeared to serve as a pull factor towards hospital death. The most likely explanation for this finding is that patients potentially in need of specialized hospital services are more likely to be admitted as a precautionary measure and at an earlier time if the travel time is high. The capacity of nurses in LTC was found to function as a pull factor towards nursing home death. Because we were not able to separate nurses by their place of work (home care or residential care), it is unclear whether this reflects a higher capacity of nurses in nursing home care or a general high nurse capacity.

The PoD occurs within a closed health service system with a zero-sum outcome, because people end up dying only in one place, and the system factors that increase the likelihood of death in one particular place will be perfectly balanced by a corresponding total reduction in the likelihood of death in the alternative locations. What is interesting, notably from a policy perspective, is how these effects are balanced between the alternative locations. For instance, while increased hospital capacity reduced the likelihood of dying in a nursing home, not only compared with dying in a hospital, but also compared with dying at home, it did not affect the likelihood of death at home versus in hospital. Similarly, it can be observed that higher relative spending on home care reduced the likelihood of dying in a nursing home compared with dying in a hospital. When these effects are observed together, a pattern of service interdependence or interaction emerges, wherein hospital and home care resources together serve as an alternative to EoL care in nursing homes.

The two 'pull factors' towards nursing home death influenced the relative risk of home death versus hospital death differently. Bed capacity in nursing homes affected the likelihood of home death, but not that of hospital death, and decreased the relative risk of home death versus hospital death. Moreover, nursing capacity in LTC appeared to influence hospital deaths the most, increasing the relative risk of home death versus hospital death. One possible explanation for these differences may be 
Table 5 Pull factors and service interactions

Service interactions

\section{Pull factors towards home death}

- Relative size of home care budget

Pull factors towards hospital death

- Nearness to local hospital

- Distance to hospital with additional functions

- Hospital beds

Pull factors towards nursing home death

- Nursing home beds

- Nurses in LTC
Reduce the relative risk of nursing home versus hospital death

Reduce the relative risk of nursing home versus home death

Reduce the relative risk of nursing home versus home death

Reduce the relative risk of home versus hospital death

Reduce the relative risk of hospital versus home death

LTC long-term care

that higher bed capacity contributed to more elderly people residing permanently in nursing homes and therefore increasing the likelihood of dying in nursing homes as opposed to a home setting, while higher rates of nursing staff in municipalities contributed to nursing homes being real alternatives to hospitals as EoL care settings. In 2011, approximately $40 \%$ of all people who died in nursing homes were on short-term stay, including observation, treatment, rehabilitation, respite and day stay. Nearly one-fifth of people dying in hospital the same year were admitted from a nursing home, of whom $53 \%$ were admitted after a short nursing home stay.

The current policy in Norway is to integrate and strengthen the competency in EoL care in the ordinary health and long-term services to ensure good and coordinated patients' pathways for all dying patients [19]. There is a limited number of dedicated palliative beds and inpatient palliative units in hospitals (110 of approximately 13,340 somatic hospital beds in 2017) and in nursing homes (approximately 440 beds of approximately 40,400 LTC beds in 2017); hospices are almost non-existent and only two of the above-mentioned units refer to themselves as hospices [19]. The Coordination reform of 2012, aimed at strengthening the local health and LTC service provision and reducing the demand for hospital services [20], supports a shift from hospital to nursing home deaths [21]. Home deaths are not common in Norway. National health authorities recommend that palliative care at home is facilitated if patients wish to spend more time at home or die at home [22], but the availability of personnel with special competence in palliative care, such as cancer nurses and mobile palliative teams, varies. Satisfactory palliative care in patients' homes depends on close collaboration and dialogue between the patient, family, home care nurses and general practitioners [23]. A recent Norwegian study estimated that the potential rate of planned home deaths for community dwellers was $24 \%$, of which only a third of deaths occurred at home [24]. The same research group found that nearly $60 \%$ of those dying at home had received domiciliary care some time during the 0-90-day period prior to their death. Moreover, they estimated that no more than $50 \%$ of all home deaths were associated with potentially planned palliative and domiciliary care [25]. The likelihood of home death increases with home visits by general practitioners in the last weeks before death; however, few people receive such visits [26].

\section{International comparisons}

A positive association between hospital bed rates and hospital deaths was also found in previous studies [16, 27-30], even when contrasted with home death $[11,14,31,32]$ or nursing home death $[14,33]$ separately. A negative association between hospital bed rates and home death was also reported [34-37]. Similar to our study, other studies did not find that hospital bed capacity influenced the likelihood of hospital death versus home death [33, 38]. However, contrary to our study, some studies did not find that hospital bed capacity influenced the likelihood of hospital death versus nursing home death [38, 39]. LTC bed availability is typically associated with higher rates of nursing home death [14, 15, 33, 39-41] and lower rates of hospital $[16,29,30]$ and home [35] deaths. However, other studies did not find any association between LTC bed availability and nursing home [38] or home [34] death. Few studies included variables capturing availability of home care services. An exception is a recent Japanese study that found a positive association between the proportion of home deaths and home care resources at the municipal level [35]. Comparison of studies is hampered by differences in study populations (e.g. general population, palliative subset, patients with cancer, patients with dementia and elderly people), institutional contexts (e.g. only institutional care), contrasts (e.g. hospital versus all, home versus all and home versus hospital), as well as methodology used (e.g. individual-level data versus aggregated proportions, multinomial or binomial logistic regression and clustering/hierarchical or not). Organizational and structural differences between countries 
are likely to lead to different results on system variables, as is often the case when several countries are included in the same study [11, 16, 30, 33, 34].

We did not find any study with analyses comparable to our analyses of the effects of travel time to hospital. Urban residency can perhaps serve as a proxy for nearness to hospital. Several studies supported more hospital deaths $[11,15,30-33,41-45]$ and fewer home deaths $[13,27,34,35,46]$ in urban areas than rural areas. Others found no or mixed effects [11, 13, 30, 33, 34, 39, 40, 44, 45, 47-49].

We identified significant context effects on PoD. We found mixed effects of the age composition variables, probably reflecting that high population numbers in different elderly age segments affect the demand for services differently. The reduced likelihood of nursing home death in municipalities with a high proportion of married adults may reflect different EoL care preferences and/or different informal care capacity. Interestingly, we found a strong effect of female work participation on nursing home death. This could reflect that nursing homes represent labour-intensive services with a high rate of female employment, and in this sense, provide another measure of nursing home capacity, and/or that high female work participation reduces preference for home death, including the informal caregivers' preferences, which have been previously shown to influence PoD [27].

Finally, the association between PoD and individual characteristics of the deceased found in this study are broadly in line with previous research findings. Lower likelihood of hospital death for women than men is in line with numerous studies on broad decedent populations $[16,43,50,51]$. Likewise, we found a higher likelihood of nursing home death for women than men, which is also a typical pattern observed in previous studies $[40,43,51,52]$. Moreover, our study demonstrated the same age effects as other studies, i.e. lower likelihood of hospital death and higher likelihood of nursing home death with higher age, at least among older age groups [43, 44, 50, 53]. While Gruneir et al. [40] found that the relative risk of hospital death versus home death decreases with age, we found, as did Reich et al. [52], that young people are more likely to die at home. Marital status also impacts PoD. We found that married persons had a higher likelihood of hospital death and lower likelihood of nursing home death than unmarried persons, which has also been observed previously $[40,51]$. However, our study found that the relative risk of home death compared with hospital death is lower for married than unmarried persons. This finding is in contrast with those of many other studies that observed that being married, or not living alone, is associated with higher likelihood of home death [54]. Our finding could reflect that home death is the exception in Norway, and that being married implies that there is another person in the home to assist with care seeking. Contrary to the main finding in the review by Costa et al. [54], we found a higher likelihood of nursing home death and a lower likelihood of home death versus hospital death for patients with cancer. Cohen et al. [16] also reported mixed results for cancer compared with other causes of death in six European countries.

The pattern of PoD for individual-level variables is likely to vary over time, as shown by Dasch et al. [43], reflecting changes in EoL organization and policy. In Norway, there has been a strong shift from hospital death towards nursing home death for patients with cancer [8], in contrast to some other countries, e.g. there was a shift from hospital to home deaths for patients with cancer in England after 2003 [55]. Norway, in general, has a low proportion of home deaths compared with other countries [10], especially for patients with cancer [13].

\section{Strengths and limitations}

A strength of our study is our comprehensive population dataset, which includes both cross-sectional and time variations in $\mathrm{PoD}$ and system characteristics. Another strength is that we explicitly modelled the two-level structure of service organizations and included variables characterizing the services at both levels, while at the same time controlling for individual and contextual factors. Typically, many studies ignore the nested structure of data and clustering of observations at higher levels. This can lead to serious problems of overconfidence in the results on especially higher-level variables because ignored clustering will generally cause standard errors of regression coefficients to be underestimated. Hence, a major strength of our study is that we used a multilevel analytical approach, allowing for variation at all levels. Finally, we applied a multinomial model, i.e. allowing for several contrasts, which provided a more comprehensive picture of system effects and service interactions.

There are some important limitations of this study. First, we only observed PoD and not the place of EoL care. Second, we did not know the quality of services received, or whether the person received special palliative care. Third, we were not able to control for place of residence, and in many cases, the nursing home will also be the place of residence. Fourth, the care needs of dying people and the length of their care needs could be a major consideration in where people die. Unexpected sudden serious health issues such as pain can influence the PoD. We were unable to control for such major influences on the PoD. Finally, this study was part of a larger project on EoL service utilization, which involved complex data linkages and time-consuming negotiations with data owners; thus, the last year covered in our data 
is 2011. Important changes in the health care system have occurred since then; most importantly, the Coordination reform was introduced in 2012. On analysing the national statistics for PoD during the period 2012-2018, we found an increase in out-of-hospital institutional deaths and a decrease in hospital and home deaths. Hence, this is a continuation of the trend found in our data from before the Coordination reform [8].

\section{Conclusions}

There is substantial variation in the PoD between municipalities and hospital districts in Norway, not only reflecting differences in decedents' characteristics, but also local circumstances, such as nearness to hospital and service capacities. It has been a core value for palliative care to enable people to make choices about their EoL care and PoD. People generally prefer to die at home, and Norway has a low proportion of home deaths compared with other countries. The proportion of home deaths varies considerably between local communities. Increasing the availability of home care services will likely provide people a more active voice in the decisions tied to their PoD, allowing more people to die at home, if that is what they prefer. In addition, these findings may have important policy implications for the EoL care in other countries with demographic and epidemiological trajectories similar to those in Norway. Further studies in other national contexts should be undertaken to support such conclusions.

\section{Abbreviations}

EoL: End of life; CoD: Cause of death; LTC: Long-term care; NCoDR: Norwegian Cause of Death Registry; PoD: Place of death;

RRR: Relative risk ratio; SSB: Statistics Norway

\section{Acknowledgements}

We thank the Norwegian Cause of Death Registry at the Norwegian Institute of Public Health for providing us with the data on place of death and characteristics of the decedents.

\section{Authors' contributions}

JK collected, prepared, and performed data analyses and contributed to the interpretation of results and writing of the manuscript. TH contributed to the interpretation of results and writing of the manuscript. Both authors read and approved the final manuscript.

\section{Funding}

The study was funded by a research grant from the Research Council of Norway (grant number 214298, project 'Utilization of health care services at the end of life').

\section{Availability of data and materials}

The analysis was based on data from the Norwegian Cause of Death Registry. Data from the registry are available for research projects approved by the registry and those that meet the requirements of the Health Research Act and the Personal Data Act.

\section{Ethics approval and consent to participate}

The study was approved by The Regional Committee for Medical and Health Research Ethics for central Norway (approval number 2012/852) and the Norwegian Social Science Data Services (the Privacy Ombudsman for
Research). Consent to participate could not be obtained as our study involved a decedent population.

\section{Consent for publication}

Not applicable.

\section{Competing interests}

The authors declare that they have no competing interests.

Received: 11 March 2019 Accepted: 1 May 2020

Published online: 24 May 2020

\section{References}

1. Hunt RW, Bond MJ, Groth RK, King PM. Place of death in South Australia. Patterns from 1910 to 1987. Med J Aust. 1999;155(8):549-53.

2. Flory J, Young-Xu Y, Gurol P, Levinsky N, Ash A, Emanuel E. Place of death: US trends since 1980. Health Aff. 2004;23(3):194-200.

3. Wilson DM, Northcott HC, Truman CD, Smith SL, Anderson MC, Fainsinger RL, Stingl MJ. Location of death in Canada - a comparison of 20th-century hospital and nonhospital locations of death and corresponding population trends. Eval Health Prof. 2001;24(4):385-403.

4. Gomes B, Calanzani N, Higginson IJ. Reversal of the British trends in place of death: time series analysis 2004-2010. Palliat Med. 2012;26(2):102-7.

5. National Center for Health Statistics. Health, United States 2010. Hyattsville: With special feature on death and dying; 2011.

6. Wilson DM, Truman CD, Thomas R, Fainsinger R, Kovacs-Burns K, Froggatt K, Justice C. The rapidly changing location of death in Canada, 1994-2004. Soc Sci Med. 2009;68(10):1752-8.

7. Wilson DM, Shen Y, Birch S. New evidence on end-of-life hospital utilization for enhanced health policy and services planning. J Palliat Med. 2017;20(7): 752-8.

8. Kalseth J, Theisen OM. Trends in place of death: the role of demographic and epidemiological shifts in end-of-life care policy. Palliat Med. 2017;31(10): 964-74.

9. Gomes B, Calanzani N, Gysels M, Hall S, Higginson I. Heterogeneity and changes in preferences for dying at home: a systematic review. BMC Palliat Care. 2013;12(1):7.

10. Broad JB, Gott M, Kim H, Boyd M, Chen H, Connolly MJ. Where do people die? An international comparison of the percentage of deaths occurring in hospital and residential aged care settings in 45 populations, using published and available statistics. Int J Public Health. 2013;58(2):257-67.

11. Pivodic L, Pardon K, Morin L, Addington-Hall J, Miccinesi G, CardenasTuranzas M, Onwuteaka-Philipsen B, Naylor W, Ramos MR, Van den Block L. Place of death in the population dying from diseases indicative of palliative care need: a cross-national population-level study in 14 countries. J Epidemiol Commun Health. 2015:70:17-24 jech-2014-205365.

12. World Health Organization: Palliative care for older people: better practices. 2011.

13. Cohen J, Houttekier D, Onwuteaka-Philipsen B, Miccinesi G, Addington-Hall J, Kaasa S, Bilsen J, Deliens L. Which patients with Cancer die at home? A study of six European countries using death certificate data. J Clin Oncol. 2010;28(13):2267-73

14. Houttekier D, Cohen J, Bilsen J, Addington-Hall J, Onwuteaka-Philipsen BD, Deliens L. Place of death of older persons with dementia. A study in five European countries. J Am Geriatr Soc. 2010;58(4):751-6.

15. Evans CJ, Ho Y, Daveson BA, Hall S, Higginson IJ, Gao W. Place and cause of death in centenarians: a population-based observational study in England, 2001 to 2010. PLoS Med. 2014;11(6):e1001653.

16. Cohen J, Bilsen J, Addington-Hall J, Lofmark R, Miccinesi G, Kaasa S, Onwuteaka-Philipsen B, Deliens L. Population-based study of dying in hospital in six European countries. Palliat Med. 2008;22(6):702-10.

17. Andersen R, Newman JF. Societal and individual determinants of medical care utilization in the United States. Milbank Mem Fund Q Health Soc. 1973; 51(1):95-124.

18. Magnussen J, Kalseth J. Fordeling av inntekter mellom regionale helseforetak (income distribution among regional health enterprises). NOU 2008:2. Samfunnsøkonomen. 2008;62(3):47-51.

19. NOU Norges offentlige utredninger (Official Norwegian Reports). På liv og død. In: Palliasjon til alvorlig syke og døende (Life and death. Palliation to seriously ill and dying people). Oslo: Helse- og omsorgsdepartementet (Ministry of Health and Care Services); 2017. 
20. Romøren TI, Torjesen DO, Landmark B. Promoting coordination in Norwegian health care. Int J Integ Care. 2011;11(Special 10th Anniversary Edition):e127.

21. Bruvik F, Drageset J, Abrahamsen JF. From hospitals to nursing homes-the consequences of the Care Coordination Reform. Sykepleien Forskning. 2017; 12(60613):(e-60613).

22. Norwegian Directorate of Health: Rapport om tilbudet til personer med behov for lindrende behandling og omsorg mot livets slutt: å skape liv til dagene (Report on services to persons in need of palliative care). Rapport IS-2278. In.

23. Danielsen BV, Sand AM, Rosland JH, Førland O. Experiences and challenges of home care nurses and general practitioners in home-based palliative care-a qualitative study. BMC Palliat Care. 2018;17(1):95

24. Kjellstadli C, Han L, Allore H, Flo E, Husebo BS, Hunskaar S. Associations between home deaths and end-of-life nursing care trajectories for community-dwelling people: a population-based registry study. BMC Health Serv Res. 2019;19(1):698.

25. Kjellstadli C, Husebø BS, Sandvik H, Flo E, Hunskaar S. Comparing unplanned and potentially planned home deaths: a population-based cross-sectional study. BMC Palliat Care. 2018;17(1):69.

26. Kjellstadli C, Allore H, Husebo BS, Flo E, Sandvik H, Hunskaar S. General practitioners' provision of end-of-life care and associations with dying at home: a registry-based longitudinal study. Fam Practice. 2019. p. cmz059.

27. Gomes B, Higginson IJ. Factors influencing death at home in terminally ill patients with cancer: systematic review. Brit Med J. 2006;332(7540):515-518A

28. Hansen SM, Tolle SW, Martin DP. Factors associated with lower rates of inhospital death. J Palliat Med. 2002;5(5):677-85.

29. Mitchell SL, Teno JM, Miller SC, Mor V. A national study of the location of death for older persons with dementia. J Am Geriatr Soc. 2005;53(2):299-305.

30. Reyniers T, Deliens L, Pasman HR, Morin L, Addington-Hall J, Frova L, Cardenas-Turanzas M, Onwuteaka-Philipsen B, Naylor W, Ruiz-Ramos M. International variation in place of death of older people who died from dementia in 14 European and non-European countries. J Am Med Dir Assoc. 2015;16(2):165-71.

31. Cohen J, Bilsen J, Hooft P, Deboosere P, van der Wal G, Deliens L. Dying at home or in an institution - using death certificates to explore the factors associated with place of death. Health Policy. 2006;78(2-3):319-29.

32. Lin HC, Lin YJ, Liu TC, Chen CS, Lin CC. Urbanization and place of death for the elderly: a 10-year population-based study. Palliat Med. 2007;21(8):705-11.

33. Houttekier D, Cohen J, Bilsen J, Addington-Hall J, Onwuteaka-Philipsen B, Deliens L. Place of death in metropolitan regions: metropolitan versus nonmetropolitan variation in place of death in Belgium, The Netherlands and England. Health Place. 2010;16(1):132-9.

34. Cohen J, Pivodic L, Miccinesi G, Onwuteaka-Philipsen B, Naylor W, Wilson D, Loucka M, Csikos A, Pardon K, Van den Block L. International study of the place of death of people with cancer: a population-level comparison of 14 countries across 4 continents using death certificate data. Brit J Cancer. 2015:113:1397-404.

35. Morioka N, Tomio J, Seto T, Yumoto Y, Ogata Y, Kobayashi Y. Association between local-level resources for home care and home deaths: a nationwide spatial analysis in Japan. PLoS One. 2018;13(8):e0201649.

36. Tang ST, Huang EW, Liu TW, Rau KM, Hung YN, Wu SC. Propensity for home death among Taiwanese Cancer decedents in 2001-2006, determined by services received at end of life. J Pain Symptom Manag. 2010;40(4):566-74

37. Yang L, Sakamoto N, Marui E. A study of home deaths in Japan from 1951 to 2002. BMC Palliat Care. 2006, 9(5):2

38. Muramatsu N, Hoyem RL, Yin HJ, Campbell RT. Place of death among older Americans - does state spending on home- and community-based services promote home death? Med Care. 2008;46(8):829-38.

39. Luta X, Panczak R, Maessen M, Egger M, Goodman DC, Zwahlen M, Stuck $A E$, Clough-Gorr K. Dying among older adults in Switzerland: who dies in hospital, who dies in a nursing home? BMC Palliat Care. 2016;15(1):83.

40. Gruneir A, Mor V, Weitzen S, Truchil R, Teno J, Roy J. Where people die - a multilevel approach to understanding influences on site of death in America. Med Care Res Rev. 2007:64(4):351-78.

41. Sleeman KE, Ho YK, Verne J, Gao W, Higginson IJ. Reversal of English trend towards hospital death in dementia: a population-based study of place of death and associated individual and regional factors, 2001-2010. BMC Neurol. 2014;14(1):59.

42. Cardenas-Turanzas M, Torres-Vigil I, Tovalin-Ahumada H, Nates JL. Hospital versus home death: results from the Mexican health and aging study. J Pain Symptom Manag. 2011;41(5):880-92.
43. Dasch B, Blum K, Gude P, Bausewein C. Place of death: trends over the course of a decade: a population-based study of death certificates from the years 2001 and 2011. Dtsch Arztebl Int. 2015;112(29-30):496.

44. Houttekier D, Cohen J, Pepersack T, Deliens L. Dying in hospital: a study of incidence and factors related to hospital death using death certificate data. Eur J Pub Health. 2013;24:ckt209.

45. Houttekier D, Cohen J, Surkyn J, Deliens L. Study of recent and future trends in place of death in Belgium using death certificate data: a shift from hospitals to care homes. BMC Public Health. 2011;11:228.

46. Pinzon LCE, Weber M, Claus M, Fischbeck S, Unrath M, Martini T, Munster E. Factors influencing place of death in Germany. J Pain Symptom Manag. 2011;41(5):893-903.

47. Burge F, Lawson B, Johnston $G$. Trends in the place of death of cancer patients, 1992-1997. Can Med Assoc J. 2003;168(3):265-70.

48. Goodridge D, Lawson J, Rennie D, Marciniuk D. Rural/urban differences in health care utilization and place of death for persons with respiratory illness in the last year of life. Rural Remote Health. 2010;10(2):1349.

49. Higginson IJ, Jarman B, Astin P, Dolan S. Do social factors affect where patients die: an analysis of 10 years of cancer deaths in England. J Public Health Med. 1999;21(1):22-8.

50. Canadian Institute for Health Information. Health care use at the end of life in western canada. Ottawa: $\mathrm{ClHI} ; 2007$.

51. Jayaraman J, Joseph K. Determinants of place of death: a population-based retrospective cohort study. BMC Palliat Care. 2013;12(1):19.

52. Reich $O$, Signorell A, Busato A. Place of death and health care utilization for people in the last 6 months of life in Switzerland: a retrospective analysis using administrative data. BMC Health Serv Res. 2013;13(1):116.

53. Håkanson C, Öhlén J, Morin L, Cohen J. A population-level study of place of death and associated factors in Sweden. Scand J Public Health. 2015;43(7): 744-51.

54. Costa V, Earle CC, Esplen MJ, Fowler R, Goldman R, Grossman D, Levin L, Manuel DG, Sharkey S, Tanuseputro P. The determinants of home and nursing home death: a systematic review and meta-analysis. BMC Palliat Care. 2016;15(1):8

55. Gao W, Ho YK, Verne J, Glickman M, Higginson IJ, Project GC. Changing patterns in place of cancer death in England: a population-based study. PLoS Med. 2013;10(3):e1001410.

\section{Publisher's Note}

Springer Nature remains neutral with regard to jurisdictional claims in published maps and institutional affiliations.

Ready to submit your research? Choose BMC and benefit from:

- fast, convenient online submission

- thorough peer review by experienced researchers in your field

- rapid publication on acceptance

- support for research data, including large and complex data types

- gold Open Access which fosters wider collaboration and increased citations

- maximum visibility for your research: over $100 \mathrm{M}$ website views per year

At BMC, research is always in progress.

Learn more biomedcentral.com/submission 